\section{FRI0331 TROUGH CONCENTRATION OF MYCOPHENOLIC ACID CORRELATES WITH RENAL FUNCTION AND SERUM ALBUMIN LEVEL IN JAPANESE PATIENTS WITH SLE}

R. Hiwa ${ }^{1}$, K. Murakami ${ }^{2}$, M. Mori ${ }^{3}$, S. Nakagawa ${ }^{3}$, S. Akizuki ${ }^{1}$, N. Kuramoto ${ }^{1}$, R. Nakashima ${ }^{2}$, M. Hashimoto ${ }^{4}$, H. Yoshifuji ${ }^{1}$, M. Tanaka ${ }^{4}$, K. Ohmura ${ }^{2}$, T. Mimori ${ }^{2}$. ${ }^{1}$ Department of Rheumatology and Clinical Immunology, Kyoto University Hospital; ${ }^{2}$ Department of Rheumatology and Clinical Immunology, Graduate School of Medicine, Kyoto University, ${ }^{3}$ Department of Clinical Pharmacology and Therapeutics, Kyoto University Hospital; ${ }^{4}$ Department for Advanced Medicine for Rheumatic Diseases, Graduate School of Medicine, Kyoto University, Kyoto, Japan

Background: Mycophenolate mofetil (MMF) is an immunosuppressant used for treatment of lupus nephritis. MMF is converted to mycophenolic acid (MPA) by esterases, which is the active metabolite with pharmacological activities. A fixed dose of 2-3 g/day is administered as remission induction therapy. ${ }^{1}$ The usefulness of therapeutic drug monitoring (TDM) of MMF has not been elucidated. Moreover, little is known about the factor that affects the concentration of MPA in Asian patients.

Objectives: The aim of this study is to investigate the factor that affects the trough concentration of MPA in Japanese patients with SLE.

Methods: We recruited the SLE cases whose trough concentrations of MPA were measured from 2014 to 2017 at Kyoto University Hospital. When trough concentrations were measured multiple times in each patient with the same dose of MMF, median concentration was used for the analyses. Linear regression analysis was performed to identify the factor that affects the trough concentration of MPA. The association of trough concentration of MPA and adverse effects of MMF was investigated as well.

Results: Total of 20 cases were recruited and 43 trough concentrations were included for the analyses. The median daily dose of MMF (g) was 1.5 (range; $0.25-3.0)$ and the median trough concentration of MPA $(\mu \mathrm{g} / \mathrm{ml})$ was 2.0 (range; 0.4-15.0). Linear regression analysis (table 1) revealed that trough concentration of MPA was correlated with daily dose of MMF ( $p=0.0081$, $r=0.40$, figure $1 A)$, serum albumin level $(p=3.3 \times 10-4, r=0.52$, figure $1 B)$ and creatinine clearance $(p=1.8 \times 10-5, r=-0.60$, figure $1 C)$. Daily dose of prednisolone and serum C4 level were correlated with trough concentration of MPA as well, though multicollinearity was found in these two variables and serum albumin or creatinine clearance. Multivariate analysis (table 2) revealed that serum albumin and creatinine clearance were independently associated with trough concentration of MPA ( $p=6.2 \times 10-4$ and $1.6 \times 10-5$, respectively). Adverse effects of MMF, such as diarrhoea and cytopenia, were not associated with trough concentration of MPA.

Abstract FRI0331 - Table 1. Linear regression analysis (Univariate analysis) of parameters influencing trough concentration of MPA

\begin{tabular}{lccc}
\hline Variables $^{*}$ & Standardised beta coefficient & P-value & Odds ratio $(95 \% \mathrm{Cl})$ \\
\hline Daily dose of MMF $(\mathrm{g})$ & 0.27 & 0.0081 & $1.31(1.08-1.59)$ \\
Serum albumin $(\mathrm{mg} / \mathrm{dl})$ & 0.30 & $3.3 \times 10-4$ & $1.35(1.16-1.57)$ \\
CCr (ml/min) & -0.062 & $1.8 \times 10-5$ & $0.94(0.91-0.96)$ \\
Age (years) & 0.0039 & 0.52 & $1.00(0.99-1.02)$ \\
BW (kg) & -0.0025 & 0.79 & $1.00(0.98-1.02)$ \\
PSL (mg/day) & -0.015 & 0.0035 & $0.99(0.98-0.99)$ \\
Serum C3 & 0.0073 & 0.055 & $1.01(1.00-1.01)$ \\
Serum C4 & 0.019 & 0.023 & $1.02(1.00-1.03)$ \\
\hline
\end{tabular}

Abstract FRI0331 - Table 2. Linear regression analysis (Multivariate analysis) of parameters influencing trough concentration of MPA

\begin{tabular}{lccc}
\hline Variables* & Beta & P-value & $\begin{array}{c}\text { Odds ratio } \\
(95 \% \mathrm{Cl})\end{array}$ \\
\hline Daily dose of MMF $(\mathrm{g})$ & 0.14 & 0.068 & $1.15(0.99-1.32)$ \\
Serum albumin $(\mathrm{mg} /$ & 0.23 & $6.2 \times 10-$ & $1.26(1.11-1.42)$ \\
$\mathrm{dl})$ & 4 & \\
$\mathrm{CCr}(\mathrm{ml} / \mathrm{min})$ & -0.053 & $1.6 \times 10-$ & $0.95(0.93-0.97)$ \\
& & 5 &
\end{tabular}

$\mathrm{BW}=$ body $\mathrm{wt}, \mathrm{PSL}=$ prednisolone, ${ }^{*}$ Standardised beta coefficient and odds ratio of $\mathrm{CCr}$ was calculated with 10 as one unit.
A

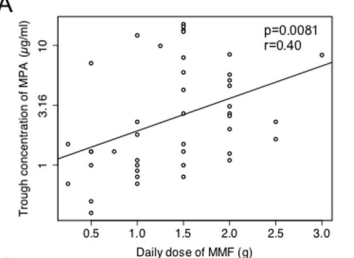

B

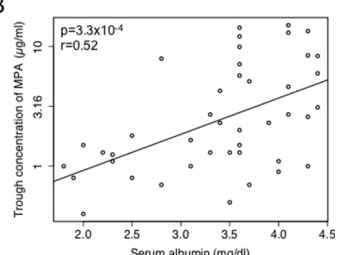

C

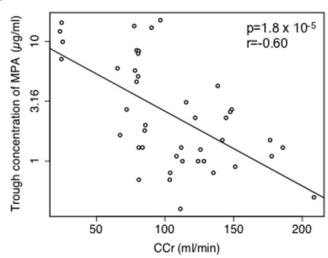

Conclusions: Trough concentration of MPA was correlated with daily dose of MMF, serum albumin level and creatinine clearance.

REFERENCE:

[1] Ann Rheum Dis 2012;71:1771-82.

Disclosure of Interest: None declared

DOI: 10.1136/annrheumdis-2018-eular.2685

\section{FRI0332 THE EXTENT OF TUBULOINTERSTITIAL INFLAMMATION PREDICTS THE PROGNOSIS OF TREATED PATIENTS WITH LUPUS NEPHRITIS}

S.J. Lee ${ }^{1}$, Y.J. Kim ${ }^{2}$, S. Jae Seok ${ }^{1}$, N.R. Kim ${ }^{1}$, E.J. Nam ${ }^{1}$, Y.M. Kang ${ }^{1}{ }^{1}$ Internal Medicine, Division of Rheumatology; ${ }^{2}$ pathology, Kyungpook National University Hospital, Daegu, Korea, Republic Of

Background: Lupus nephritis is common clinical manifestation and contributes significantly to mortality of systemic lupus erythematosus (SLE)

Objectives: Recently it has been reported that severity of tubulointerstitial inflammation (TII) predicts subsequent renal failure. However, it has not yet been reported what histologic features affect the survival rate in patients with lupus nephritis who had conventional treatment.

Methods: Seventy-six patients with lupus nephritis, who had conventional treat ment and renal biopsy, were enrolled in this study. The extent of tubulointerstitial lymphocytic infiltrates was semi-quantitated (grade 1-4) using standard histochemical staining. This was then compared to other established lupus nephritis classification (ISN/RPN classification) which focuses on histologic changes of the glomerulus as well as clinical and laboratory characteristics. Follow-up data were obtained and survival analysis was carried out to determine the predictive values for subsequent mortality.

Results: TII was a common pathologic finding, $64 \%$ percent of biopsy samples were graded as $1,11 \%$ as $2,14 \%$ as 3 , and $11 \%$ as 4 . In $29 \%$ of biopsies (22/76), there were well circumscribed lymphocyte aggregates in tubulointerstitium and $5 \%$ of biopsies (4/76), structures like germinal centre (GC) were observed. When TII was divided into mild (grade 1-2) and severe (grade 3-4), lymphocyte aggregates and GC formation were more common in patients with severe TII $(15 / 19,4$ / 19) than those with mild TII $(7 / 57,0 / 57)(p<0.001$ and $p=0.004$, respectively). Patients with severe TII or lymphocyte aggregates were significantly higher in serum creatinine, but not with double-stranded DNA (ds DNA) antibodies, serum complement 3, SLE disease activity (SLEDAI) and degree of proteinuria at the time of biopsies compared to those without. The mean follow-up time was 62.9 \pm 47.0 months and overall, 9 patients died as a result of disease progression $(n=6)$ and infection $(n=3)$. Patients with severe TII, lymphocyte aggregates or GC formation were at greater risk for mortality compared to those without. However, both glomerular proliferation and laboratory markers including baseline ds DNA, complement, SLEDAI and degree of proteinuria did not affect on long term mortality. After multivariate logistic analysis including SLEDAI and histologic features, only GC formation provided poor prognostic information for mortality (hazard ratio $24.5,95 \%$ confidence interval 2.2-274.6; $p=0.009$ ).

Conclusions: TIl severity, especially GC formation, was independent predictor for a worse outcome in lupus nephritis patients with conventional treatment. A larger study is needed to confirm whether the presence of GC formation influences disease outcome.

Disclosure of Interest: None declared

DOI: 10.1136/annrheumdis-2018-eular.6441 


\section{FRI0333 B-CELLS DEPLETION AS RESCUE THERAPY FOR EXTRA-CRITERIA MANIFESTATIONS OF PRIMARY ANTIPHOSPHOLIPID SYNDROME}

S. Sciascia ${ }^{1}$, M. Radin ${ }^{1}$, I. Cecchi ${ }^{1}$, E. Rubini ${ }^{1}$, D. Rossi ${ }^{2}$, M. Bazzan $^{3}$, D. Roccatello ${ }^{1}{ }^{1}$ Department of Clinical and Biological Sciences, Università Degli Studi Di Torino; ${ }^{2}$ Ospedale S. Giovanni Bosco, Turin, Italy; ${ }^{3}$ UOSD Hematology and Thrombosis Unit, Ospedale S. Giovanni Bosco, Turin, Italy

Background: While immunosuppressive drugs may be helpful in patients with active systemic autoimmune diseases, their use in antiphospholipid syndrome (APS) is still controversial, and mainly limited to very selected cases of catastrophic APS or in severe cases refractory to standard therapy. ${ }^{1}$ B-cells are likely to play a central role in the generation of the aPL-induced clinical manifestations of the disease, so they might constitute a logical therapeutic target in APS.

Objectives: To investigate PAPS patients with extra-criteria manifestations of APS treated with Rituximab (RTX) as a rescue therapy.

Methods: We retrospectively retrieved data from patients who attended the $S$. Giovanni Bosco Hospital, Turin, Italy, who met the following inclusion criteria: a) persistent aPL positivity and fulfilled the Sydney criteria for PAPS $\left[{ }^{2}\right.$ b) presented with at least 1 extra-criteria manifestation; c) were treated with RTX as a rescue therapy (e.g. because they were refractory/intolerant/contraindicated to standard therapy) for the management of extra-criteria manifestations of APS.

Results: This retrospective study included 7 consecutive PAPS patients [median age 53 (range 38-66), female 6:1]. Table 1 resumes the characteristics of the PAPS patients included in the study. Six patients presented with severe thrombocytopenia (plts $<50.000 / \mathrm{mm}^{3}$ ) and 1 patient presented with recurrent superficial venous thrombosis ( 3 events in 6 months despite ongoing anticoagulation therapy with VKA). Previous therapies included intravenous immunoglobulins (5 patients) and high doses of steroids ( 3 patients). One patient received RTX as rescue therapy as a steroid-sparing agent because of the high cardiovascular risk (high body mass index, uncontrolled arterial hypertension, and diabetes). We observed a full response after treatment with RTX in 6 out of 7 patients $(86 \%, 5$ with thrombocytopenia and 1 with recurrent superficial thrombosis). One patient who did not respond to the B-cell depletion therapy, and was treated with a splenectomy 1 month after RTX therapy and platelets levels normalised 3 months after the procedure. Overall, median time free from relapse was 27.5 months (range 4-97), no adverse events were reported, no patients developed infections.

Abstract FRI0333 - Table 1. Patients with PAPS with extra-criteria manifestations that followed a B-cells depleting protocol from the experience of our centre

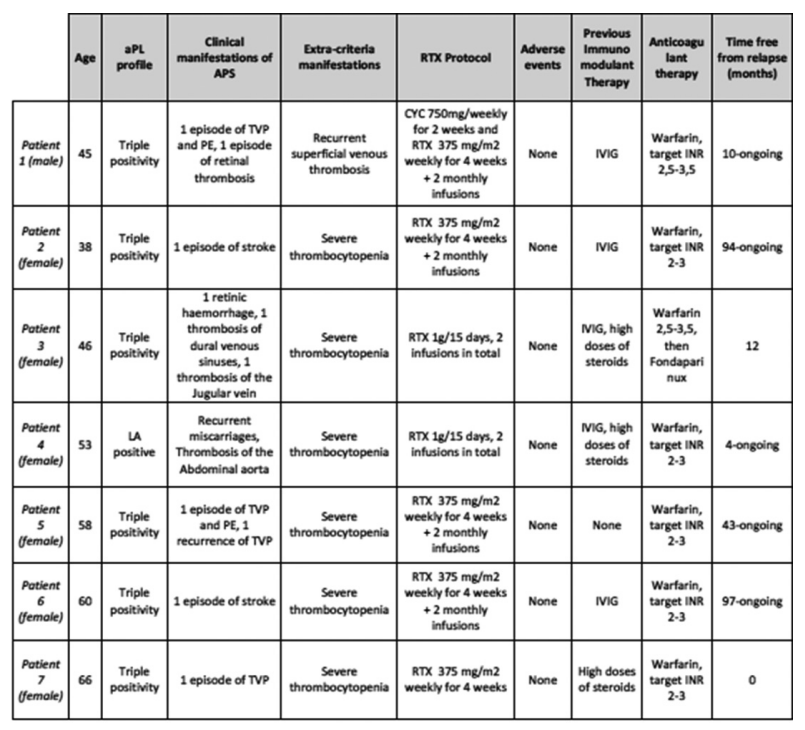

APS Antiphospholipid Syndrome, UC undifferentiated connective tissue disease, CYC cyclophosphamide, RTX rituximab, AZA

azathioprine, MTX methotrexate, OVT deep vein thrombosis, PE pulmonary embolism

Conclusions: In selected case of patients with PAPS, RTX can represent a safe and efficacious therapeutic tool to manage the extra-criteria manifestations of the syndrome, especially when standard approaches have failed or cannot be pursued.

\section{REFERENCES:}

[1] Erre GL, Pardini S, Faedda R, Passiu G. Effect of rituximab on clinical and laboratory features of antiphospholipid syndrome: a case report and a review of literature. Lupus 2008:17:50-5. doi:10.1177/0961203307085251

[2] Miyakis S, Lockshin MD, Atsumi T, Branch DW, Brey RL, Cervera R, et al. International consensus statement on an update of the classification criteria for definite antiphospholipid syndrome (APS). J Thromb Haemost 2006;4:295-306. doi:10.1111/j.1538-7836.2006.01753.x

Disclosure of Interest: None declared

DOI: 10.1136/annrheumdis-2018-eular.2157

\section{FRI0334 COMPARISON OF DIFFERENT DEFINITIONS OF REMISSION IN SYSTEMIC LUPUS ERYTHEMATOSUS (SLE) - A STUDY BASED ON THE BLISS-76 CLINICAL TRIAL}

S. Emamikia ${ }^{1}$, C. Gentline ${ }^{1}$, E. Arkema ${ }^{2}$, L. Arnaud ${ }^{3}$, K. Chatzidionysiou ${ }^{1}$, R. van Vollenhoven ${ }^{1,4}$. ${ }^{1}$ Department of Medicine, ${ }^{2}$ Clinical Epidemiology Unit, Karolinska Institute, Stockholm, Sweden; ${ }^{3}$ Department of Rheumatology, Université de Strasbourg, Strasbourg, France, ${ }^{4}$ Amsterdam Rheumatology and Immunology Center, Amsterdam, Netherlands

Background: Standardisation of a definition of disease remission in SLE is one of the most important unmet needs in rheumatology and up to today there is no gold standard for the definition of remission. ${ }^{1}$

Objectives: An international task force consisting of 60 rheumatologists, nephrologists, dermatologists, clinical immunologists and patient representatives agreed on various definitions of remission in SLE (DORIS). ${ }^{2}$ Our aim was to apply these definitions on a clinical trial.

Methods: This is a post-hoc analysis of a prospective randomised controlled tria (RCT) in SLE, the BLISS-76 clinical trial. ${ }^{3}$ We have applied two DORIS definitions (table 1) at three time points, week (wk) 24, 52 and 76. The patient could be in remission on or off treatment. Remission on treatment allowed maintenance antimalarials, low dose glucocorticoids (GCs) (prednisone $\leq 5 \mathrm{mg} /$ day or equivalent), maintenance immunosuppressives and maintenance biologics. Remission off treatment allowed maintenance anti-malarials only. Additionally, we applied each definition where the remission on treatment allowed a GC dose $\leq 10 \mathrm{mg} /$ day (not a part of the original DORIS-definitions).

Abstract FRI0334 - Table 1. DORIS definitions of remission in SLE

\begin{tabular}{|c|c|c|c|c|}
\hline Definition & 1a & $1 \mathrm{~b}$ & $3 a$ & 3b \\
\hline CSLEDAI $=0$ & $\mathrm{v}$ & $\mathrm{v}$ & - & - \\
\hline$P h G A<0.5$ & v & $v$ & $\checkmark$ & $v$ \\
\hline Serology & Regardless & Normal & Regardless & Normal \\
\hline BILAG D/E only & $\cdot$ & • & $v$ & v \\
\hline \multicolumn{5}{|c|}{$\begin{array}{l}\text { cSLEDAI: clinical Systemic Lupus Erythematosus Discase Activity Index; } \\
\text { PhGA: Physician Global Assessment; } \\
\text { BILAG: British Isles Lupus Assessment Group } \\
\text { Note: Anti-double stranded DNA and complement (C3 and C4) is included in serology. These definitions were } \\
\text { first tested (a) regardless of serology and then (b) normal serology (negative anti-dsDNA antibodies AND } \\
\text { normal complement). }\end{array}$} \\
\hline
\end{tabular}

Abstract FRI0334 - Table 2. Percent of Patients who started the BLISS-76 trial $(n=819)$ who were in remission at week 24 , week 52 , and week 76 using different definitions

\begin{tabular}{|c|c|c|c|c|c|c|}
\hline & $\begin{array}{l}\text { Definition la, } \\
\text { On treatment } \\
\text { (GCss } 5 \text { mg } \\
\text { allowed) }\end{array}$ & \begin{tabular}{|l|} 
Definition \\
1a, On \\
treatment \\
(GCs $\leq 10 \mathrm{mg}$ \\
allowed) \\
\end{tabular} & \begin{tabular}{|l|} 
Definition 1a, \\
Off treatment
\end{tabular} & \begin{tabular}{|l|} 
Definition Ib, \\
On treatment \\
(GCs $\leq 5 \mathrm{mg}$ \\
allowed)
\end{tabular} & \begin{tabular}{|l|} 
Definition Ib, On \\
treatment \\
(GCs $\leq 1 \mathrm{mg}$ \\
allowed)
\end{tabular} & $\begin{array}{l}\text { Definition lb, } \\
\text { Off treatment }\end{array}$ \\
\hline $\begin{array}{l}\% \text { \%(n) in } \\
\text { remission W24 }\end{array}$ & $\begin{array}{l}.2 \\
(34)\end{array}$ & $\begin{array}{l}7.3 \\
(60)\end{array}$ & $\begin{array}{l}0.4 \\
\text { (3) }\end{array}$ & $\begin{array}{l}1.0 \\
(8)\end{array}$ & $\begin{array}{l}1.7 \\
\text { (14) }\end{array}$ & $\begin{array}{l}0.1 \\
\text { (1) }\end{array}$ \\
\hline $\begin{array}{l}\% \text { (n) in } \\
\text { remission WS2 }\end{array}$ & $\begin{array}{l}7.4 \\
\text { (61) }\end{array}$ & $\begin{array}{l}\begin{array}{l}11.8 \\
(97)\end{array} \\
\text { (1) }\end{array}$ & $\begin{array}{l}0.7 \\
\text { (6) }\end{array}$ & $\begin{array}{l}2.6 \\
\text { (21) }\end{array}$ & $\begin{array}{l}3.2 \\
(26)\end{array}$ & $\begin{array}{l}0.5 \\
\text { (4) }\end{array}$ \\
\hline \multirow[t]{2}{*}{$\begin{array}{l}\%(\mathrm{n}) \text { in } \\
\text { remission W76 }\end{array}$} & $\begin{array}{l}9.5 \\
(78)\end{array}$ & $\begin{array}{l}13.8 \\
\text { (113) }\end{array}$ & $\begin{array}{l}1.0 \\
(8)\end{array}$ & $\begin{array}{l}3.2 \\
(26)\end{array}$ & $\begin{array}{l}4.4 \\
(36)\end{array}$ & $\begin{array}{l}0.4 \\
\text { (3) }\end{array}$ \\
\hline & $\begin{array}{l}\text { Definition 3a, } \\
\text { On treatment } \\
\text { (GCs } \leq 5 \mathrm{mg} \\
\text { allowed) }\end{array}$ & \begin{tabular}{|l|} 
Definition \\
3a, on \\
treatment \\
(GCSs $10 \mathrm{mg}$ \\
allowed)
\end{tabular} & \begin{tabular}{|l|} 
Definition 3a, \\
Off treatment
\end{tabular} & \begin{tabular}{|l} 
Definition 3b, \\
On treatment \\
(GCs $\leq 5 \mathrm{mg}$ \\
allowed)
\end{tabular} & \begin{tabular}{|l|} 
Definition $3 \mathrm{~b}$, On \\
treatment (GCs \\
$\leq 10 \mathrm{mg}$ allowed) \\
\end{tabular} & $\begin{array}{l}\text { Definition 3b, } \\
\text { Off treatment }\end{array}$ \\
\hline $\begin{array}{l}\% \text { \%(n) in } \\
\text { remission W24 }\end{array}$ & $\begin{array}{l}0.9 \\
\text { (7) }\end{array}$ & $\begin{array}{l}2.2 \\
(18)\end{array}$ & 0 & $\begin{array}{l}0.5 \\
\text { (4) }\end{array}$ & $\begin{array}{l}0.6 \\
\text { (5) }\end{array}$ & 0 \\
\hline $\begin{array}{l}\%(n) \text { in } \\
\text { remission W52 }\end{array}$ & $\begin{array}{l}1.3 \\
\text { (11) }\end{array}$ & $\begin{array}{l}2.8 \\
(23)\end{array}$ & $\begin{array}{l}0.1 \\
\text { (1) }\end{array}$ & $\begin{array}{l}0.7 \\
(6)\end{array}$ & $\begin{array}{l}1.1 \\
(9)\end{array}$ & $\begin{array}{l}0.1 \\
\text { (1) }\end{array}$ \\
\hline $\begin{array}{l}\%(\mathrm{n}) \text { in } \\
\text { remission W76 }\end{array}$ & $\begin{array}{l}2.9 \\
(24)\end{array}$ & $\begin{array}{l}.5 \\
(37)\end{array}$ & $\begin{array}{l}0.1 \\
\text { (1) }\end{array}$ & $\begin{array}{l}1.6 \\
(13)\end{array}$ & $\begin{array}{l}2.3 \\
(19)\end{array}$ & $\begin{array}{l}0.1 \\
\text { (1) }\end{array}$ \\
\hline
\end{tabular}

Def1a:cSLEDAl=0, PhGA $<0.5$ and normal serology

Def $1 \mathrm{~b}$ : cSLEDAl=0, PhGA $<0.5$ and regardless of serology

Def3a:BILAG D/E only, PhGA $<0.5$ and normal serology

Def $3 b$ : BILAG D/E only, PhGA $<0.5$ and regardless of serology

GCs: Glucocorticoids

On treatment: maintenance anti-malarials, low dose glucocorticoids (prednisone $\leq 5 \mathrm{mg} /$ day or equivalent), maintenance immunosuppressives, and maintenance biologics are allowed. Off treatment: maintenance anti-malarials only is allowed.

Results: There were 819 patients enrolled in BLISS-76. The proportions of patients that fulfilled remission according to the above definitions are shown in table 2 . The highest point prevalence $(9.5 \%)$ was when definition 1a on treatment was applied at wk 76. As expected, even more patients fulfilled definition 1a when a GC dose $\leq 10 \mathrm{mg} /$ day was allowed at wk 76 (13.8\%). More patients fulfilled the 